\title{
Intact Fibroblast Growth Factor 23 Measurement
}

National Cancer Institute

\section{Source}

National Cancer Institute. Intact Fibroblast Growth Factor 23 Measurement. NCI

Thesaurus. Code C135420.

The determination of the amount of the intact fibroblast growth factor 23 in a biological sample. 